\title{
Endoscopic ultrasonography compared with multidetector computed tomography for the preoperative staging of gastric cancer: a meta-analysis
}

Run-Cong Nie ${ }^{1 \dagger}$, Shu-Qiang Yuan ${ }^{1 \dagger}$, Xiao-Jiang Chen ${ }^{1 \dagger}$, Shi Chen², Li-Pu Xu', Yong-Ming Chen ${ }^{1}$, Bao-Yan Zhu', Xiao-Wei Sun ${ }^{1}$, Zhi-Wei Zhou ${ }^{1}$ and Ying-Bo Chen ${ }^{1 *}$

\begin{abstract}
Background: The current study sought to perform a meta-analysis to compare the preoperative staging of endoscopic ultrasonography (EUS) and multidetector computed tomography (MDCT) in gastric carcinoma.

Methods: Articles published between January 1, 2000, and April 1, 2016, that compared EUS with MDCT were included, and data were presented as $2 \times 2$ tables. The sensitivities, specificities and summary receiver operating characteristic (ROC) curves for $\mathrm{T}$ and $\mathrm{N}$ staging were calculated using a bivariate mixed effects model. Data were weighted by generic variance and then pooled by random-effects modeling.

Results: Eight studies comprising 1736 patients were included in this meta-analysis. For T1 staging, the sensitivity value for EUS (82\%) was significantly higher than that for MDCT (41\%) (relative risk (RR): 2.06, 95\% confidence interval $(\mathrm{Cl}) 1.07-3.94 ; P=0.030$ ). For lymph node involvement, the sensitivity value for EUS (91\%) was also significantly higher than that for MDCT (77\%) (RR 1.14,95\% Cl 1.05-1.23; $P=0.001$ ). However, the specificity values of both EUS and MDCT were quite low, at 49 and 63\%, respectively. No significant differences in T2-4 staging between EUS and MDCT were noted.
\end{abstract}

Conclusion: This meta-analysis indicates that EUS may be superior to MDCT in preoperative $\mathrm{T} 1$ and $\mathrm{N}$ staging. Additionally, the low specificity values of EUS and MDCT for N staging merits attention.

Keywords: Gastric carcinoma, Multidetector computed tomography, Endoscopic ultrasonography, Staging, Meta-analysis

\section{Background}

On a worldwide scale, gastric cancer is the fourth most common malignancy and the third leading cause of cancer-related death [1]. With early diagnosis, more accurate preoperative staging and standardized curative surgery, gastric cancer patients receive more appropriate and less invasive treatment approaches, thus promoting an increase in overall survival [2-4]. Among these factors, accurate preoperative assessment of tumor invasion

\footnotetext{
* Correspondence: chenyb@sysucc.org.cn

${ }^{\dagger}$ Equal contributors

${ }^{1}$ Sun Yat-sen University Cancer Center; State Key Laboratory of Oncology in South China; Collaborative Innovation Center for Cancer Medicine, 651 E Dongfeng Road, Guangzhou, Guangdong 510060, China

Full list of author information is available at the end of the article
}

depth and lymph node metastasis is a fundamental first step in an optimal therapeutic approach. According to the new National Comprehensive Cancer Network $(\mathrm{NCCN})$ practice guidelines for gastric cancer for clinical Tis or T1a gastric cancer patients, endoscopic mucosal resection (EMR) or endoscopic submucosal dissection (ESD) can be considered adequate therapy when the lesion is smaller than $2 \mathrm{~cm}$ without associated ulcer formation [5-7]. Results from two large phase III randomized controlled trials demonstrated that locally advanced gastric cancer patients could benefit from neoadjuvant chemotherapy $[8,9]$. As a result, for patients who are diagnosed with clinical T2 disease or higher or with positive lymph node involvement, NCCN practice 
guidelines suggest that perioperative chemotherapy is a preferred treatment strategy.

Regarding the imaging for preoperative staging of gastric cancer, endoscopic ultrasonography (EUS) and multidetector computed tomography (MDCT) are the most commonly used techniques [10], especially in China. However, previous studies have reported conflicting results in preoperative staging between these two modalities [10-16]. Moreover, NCCN practice guidelines for gastric cancer do not recommend specific modalities or workup pathways [7]. Therefore, the purpose of our study was to perform a meta-analysis to compare EUS with MDCT for the preoperative staging of gastric carcinoma.

\section{Methods}

\section{Search strategy}

The PubMed and Web of Science databases were searched systematically for all relevant articles published between January 1, 2000, and April 1, 2016, that compared EUS with MDCT. The following key words were used in these literature searches: "EUS" OR "endoscopic ultrasound" OR "endosonography" OR "endoscopic ultrasonography" OR "computed tomography" OR "contrast-enhanced computed tomography" OR "multidetector computed tomography" and "stomach cancer" OR "gastric cancer" OR "gastric adenocarcinoma" and "sensitivity" OR "specificity" OR "accuracy" OR "diagnostic". The reference lists of the articles retrieved were manually reviewed to identify additional relevant references.

\section{Study inclusion and exclusion criteria}

Studies were included if they met the following criteria: (1) histologically proven gastric adenocarcinoma in more than 30 patients without any preoperative chemotherapy and/or radiation therapy; (2) histopathologic findings after gastrectomy used as the reference standard; and (3) data sufficient to construct a $2 \times 2$ contingency table. Studies were excluded based on the following exclusion criteria: (1) animals or ex vivo studies; (2) review articles, meta-analyses, abstracts, case reports, letters, and conference proceedings; and (3) studies published in a language other than English. The most recent or complete article was used if multiple articles described the same population.

\section{Data extraction}

Data were extracted and summarized independently by two authors (RC, Nie and S, Chen). Two adjudicating senior authors (SQ, Yuan and $\mathrm{YB}, \mathrm{Chen}$ ) resolved any disagreement. The following data from each included study were extracted: first author, study design, year of publication, and sample size (number of patients).

\section{Study quality}

Considering the lack of consensus to assess the quality of non-randomized clinical trials, studies used in this

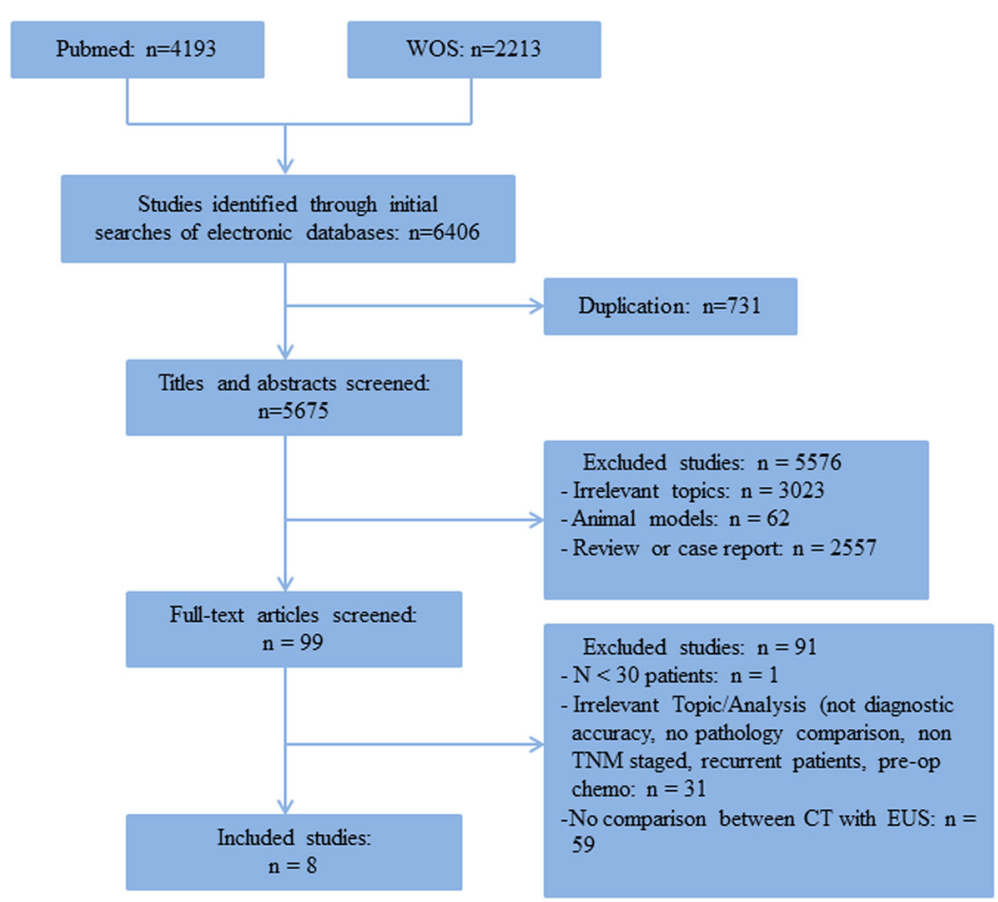

Fig. 1 Flow diagram of the studies identified in the meta-analysis. MDCT, multidetector computed tomography; EUS, Endoscopic ultrasonography 
Table 1 Characteristics of included studies

\begin{tabular}{|c|c|c|c|c|c|c|c|}
\hline Study & Study type & No. of patient & Year & EUS MHz & Patient selection & Blinded & Reference tes \\
\hline Habermann et al. & $\mathrm{R}$ & 51 & 2004 & $7.5 / 12.0$ & No & Yes & Yes \\
\hline Polkowski et al. & P & 88 & 2004 & $7.5 / 12.0$ & No & Yes & Yes \\
\hline Ahn et al. & $P$ & 434 & 2009 & $5 / 12.0$ & Unknown & Yes & Yes \\
\hline SW Hwang et al. & $\mathrm{R}$ & 277 & 2010 & $5 / 7.5 / 12 / 20$ & No & Unknown & Yes \\
\hline Furukawa et al. & $\mathrm{R}$ & 175 & 2011 & $5 / 7.5 / 12 / 20$ & No & Yes & Yes \\
\hline Feng et al. & $\mathrm{R}$ & 610 & 2013 & $5 / 7.5 / 12 / 20$ & No & Yes & Yes \\
\hline Fairweather et al. & $\mathrm{R}$ & 49 & 2015 & $5 / 10$ & Unknown & Yes & Yes \\
\hline Giganti et al. & $P$ & 52 & 2016 & $5 / 10$ & No & Yes & Yes \\
\hline
\end{tabular}

$R$ retrospective study, $P$ prospective study

meta-analysis were selected based on data completeness and inclusion criteria.

\section{Statistical analyses}

A bivariate mixed effects model was performed to acquire summary estimates of sensitivity and specificity and to fit summary receiver operating characteristic (ROC) curves. We used the relative risk (RR) for the comparison of the sensitivity and specificity of the two modalities. Our studies reported results with $95 \%$ confidence intervals (CIs). We used the $\chi^{2}$ test to assess heterogeneity with the level of significance set at $10 \%$, and the $I^{2}$ statistic was used to quantify heterogeneity.

The fixed-effects model was used if there was no significant heterogeneity between studies; otherwise, the random-effects model was performed [17]. We also used funnel plots to screen for publication bias if more than ten studies were included. Egger's linear regression was used to test the effect of publication bias [18].

Analyses were performed using STATA SE 12.0 for Windows (StataCorp LP, College Station, TX).

\section{Results}

\section{Study selection}

A total of 5675 articles were identified using our search strategy. After screening their titles and abstracts, 5576 identical studies were excluded. The remaining 99 studies were fully reviewed. Ultimately, eight studies including
1736 cases were included for the final analysis $[10-16,19]$ (Fig. 1). The characteristics of the included studies are presented in Table 1. Among the eight studies, three were prospective studies [10-12], and five were retrospective studies $[13-16,19]$. Agreement between the two reviewers was $97 \%$ for study selection.

\section{Summary estimates of sensitivity and specificity}

The overall sensitivity and specificity of EUS and MDCT for gastric cancer patients are presented in Table 2.

\section{T1 invasion}

The sensitivity value for EUS (82\%) was significantly higher than that for MDCT (41\%) (RR 2.06, 95\% CI $1.07-3.94 ; P=0.030$ ), with significant between-study heterogeneity $\left(\chi^{2}=329.32, \quad P<0.001 ; I^{2}=98.5 \%\right)$. No significant publication bias was observed $(P=0.106)$. The specificity values for EUS and MDCT were 89 and 97\%, respectively, and this difference was not significant (RR 0.95, 95\% CI 0.87-1.03; $P=0.228$ ) (Fig. 2).

\section{T2 invasion}

The sensitivity value for EUS (72\%) was marginally higher than that for MDCT (48\%) (RR 1.48, 95\% CI $0.99-2.20 ; P=0.056)$, with significant between-study heterogeneity $\left(\chi^{2}=19.41, P=0.002 ; I^{2}=74.2 \%\right)$. The specificity values for EUS (84\%) and MDCT (86\%) were similar (RR 0.98, 95\% CI 0.92-1.06; $P=0.629$ ) (Fig. 3).

Table 2 Sensitivity and specificity for EUS and MDCT imaging to diagnose T and N staging

\begin{tabular}{|c|c|c|c|c|c|c|}
\hline \multirow[t]{2}{*}{ Stage } & \multicolumn{3}{|c|}{ Sensitivity (\%) } & \multicolumn{3}{|c|}{ Specificity (\%) } \\
\hline & EUS & $\mathrm{MDCT}$ & $P$ value & EUS & $\mathrm{MDCT}$ & $P$ value \\
\hline $\mathrm{T1}$ & 82 (64-92) & $41(13-77)$ & 0.030 & 89 (52-98) & $97(80-100)$ & 0.228 \\
\hline $\mathrm{T} 2$ & $72(54-85)$ & $48(29-68)$ & 0.056 & $84(80-88)$ & 86 (78-92) & 0.629 \\
\hline T3 & $68(52-80)$ & $64(37-84)$ & 0.749 & 87 (77-93) & 87 (70-95) & 0.455 \\
\hline T4 & $52(25-78)$ & $61(29-86)$ & 0.613 & 97 (90-99) & 97 (92-99) & 0.731 \\
\hline N & 91 (81-96) & $77(66-86)$ & 0.001 & $49(20-79)$ & $63(42-80)$ & 0.079 \\
\hline
\end{tabular}

MDCT multidetector computed tomography, EUS Endoscopic ultrasonography 


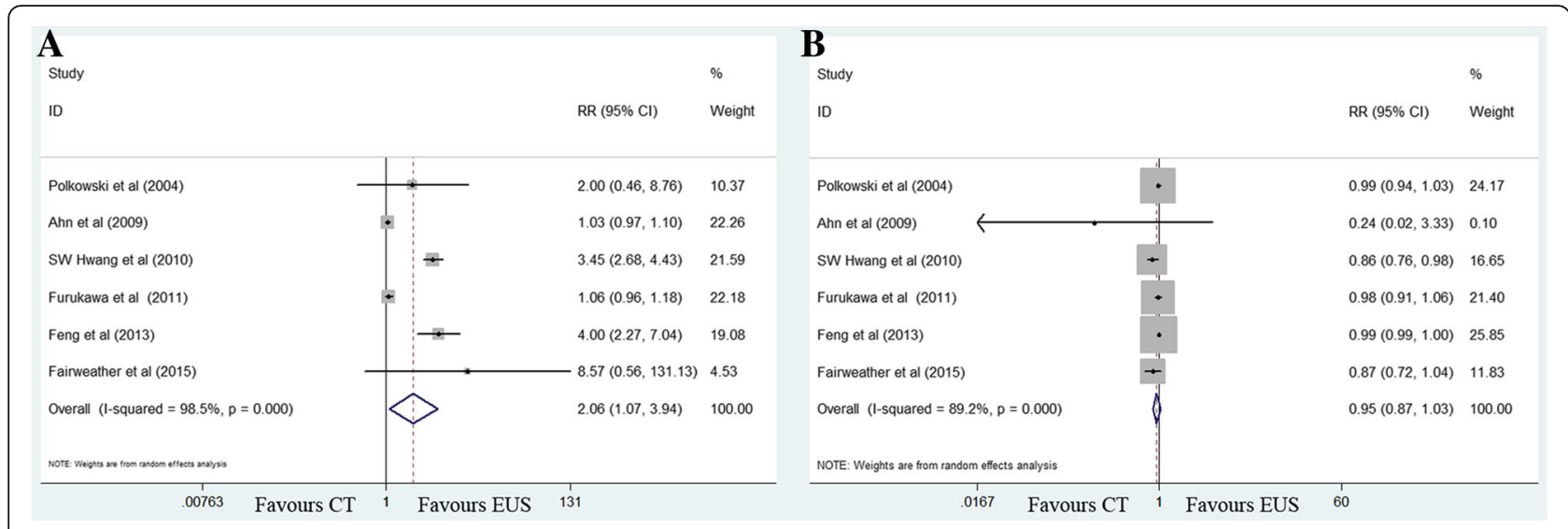

Fig. 2 Forest plots of sensitivity (a) and specificity (b) for T1 staging. MDCT, multidetector computed tomography; EUS, Endoscopic ultrasonography. RR, relative risk; $\mathrm{Cl}$, confidence interval

\section{T3 invasion}

No difference in sensitivity for EUS (68\%) and MDCT (64\%) was noted (RR 1.05, 95\% CI 0.77-1.43; $P=0.749$ ). EUS and MDCT imaging exhibited similar specificity estimates of $87 \%$ (Fig. 4).

\section{T4 invasion}

Sensitivity estimates between the two imaging modalities were comparable: $52 \%$ for EUS and $61 \%$ for MDCT. Specificity values were also comparable: $97 \%$ for both EUS and MDCT (Fig. 5).

\section{Lymph node involvement}

The sensitivity value for EUS (91\%) was significantly higher than that for MDCT (77\%) (RR 1.14, 95\% CI $1.05-1.23 ; P=0.001)$, with moderate between-study heterogeneity $\left(\chi^{2}=12.68, P=0.048 ; I^{2}=52.7 \%\right)$. No significant publication bias was observed $(P=0.073)$. Specificity was comparable between modalities, with values of $49 \%$ for EUS and $63 \%$ for MDCT (RR 0.80, 95\% CI $0.62-1.03 ; P=0.079$ ) (Fig. 6).

\section{Summary ROC curves}

Summary ROC curves of T1 invasion and lymph node involvement are presented in Figs. 7 and 8. A summary ROC curve located near the upper left corner with an increased area under the curve (AUC) indicates a better diagnostic modality. Summary ROC curves for T1 invasion using EUS were located closer to the upper left corner than those using MDCT, indicating the better diagnostic performance of EUS (Fig. 7). In addition, summary ROC curves demonstrated the better diagnostic performance of EUS than that of MDCT for lymph node involvement (Fig. 8).

\section{Discussion}

Accurate preoperative evaluation for $\mathrm{T}$ and $\mathrm{N}$ staging of gastric cancer relies on precise imaging. Among various imaging modalities, EUS and computed tomography

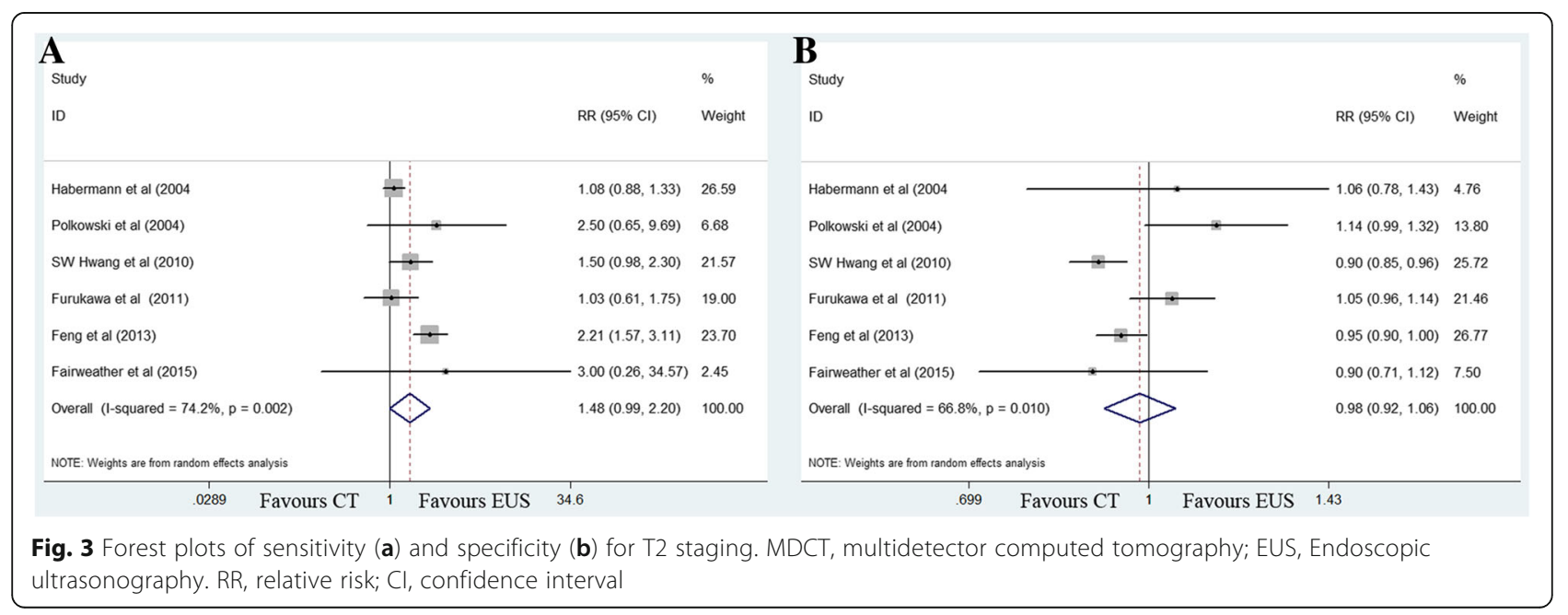




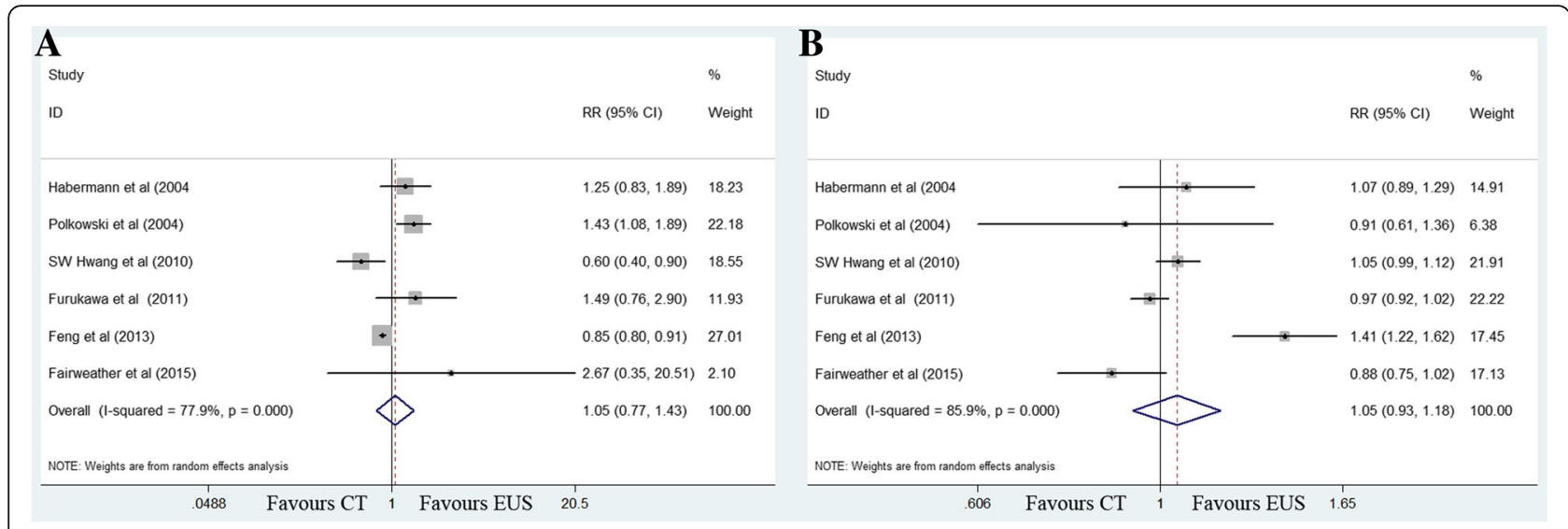

Fig. 4 Forest plots of sensitivity (a) and specificity (b) for T3 staging. MDCT, multidetector computed tomography; EUS, Endoscopic ultrasonography. RR, relative risk; Cl, confidence interval

(CT) are the most common and valuable tools for the preoperative evaluation of gastric cancer. EUS was first introduced in clinical practice in the 1980s and exhibits high accuracy in detecting the depth of gastric cancer $[20,21]$. Moreover, EUS shows greater accuracy than incremental CT for both the $\mathrm{T}$ and $\mathrm{N}$ staging assessment. However, MDCT exhibits a remarkably improved resolution and an accuracy and diagnostic performance similar to EUS [22-24]. Previous studies have reported conflicting results in preoperative staging between EUS and MDCT [10-16, 19]. This meta-analysis of three prospective studies and five retrospective studies including 1736 patients comparing the sensitivity and specificity of EUS and MDCT demonstrated that EUS was superior to MDCT in preoperative $\mathrm{T} 1$ and $\mathrm{N}$ staging. No significant differences in T2-4 staging were noted between EUS and MDCT.

With the increase in global aging, the proportion of gastric cancer patients older than 70 years is increasing, resulting in an increase in morbidity and mortality after curative gastrectomy. This trend has led to the need for less invasive treatment options, such as EMR and ESD, for early gastric cancer (EGC). Isomoto et al. demonstrated that 5-year overall and disease-specific survival rates after ESD reached 97.1 and 100\%, respectively, indicating the excellent prognosis of ESD for EGC [6]. However, the standard imaging modality for clinical assessment of EGC remains debatable. Whether EUS is more accurate than MDCT in diagnosing EGC remains unknown [12, 15, 25]. This meta-analysis demonstrated that the sensitivity of EUS was significantly higher than that of MDCT for EGC, indicating that EUS was a preferred imaging modality in diagnosing EGC. For example, the EUS result was more reliable if a gastric cancer patient was preoperatively staged as $\mathrm{T} 1$ using EUS but T2 using MDCT. The reasons why EUS was superior to MDCT for T1 staging are as follows: (1) most EGC cases were easily treated by MDCT because EGC appeared to have small size without obvious enhancement of mucosa; and (2) the integrality of the

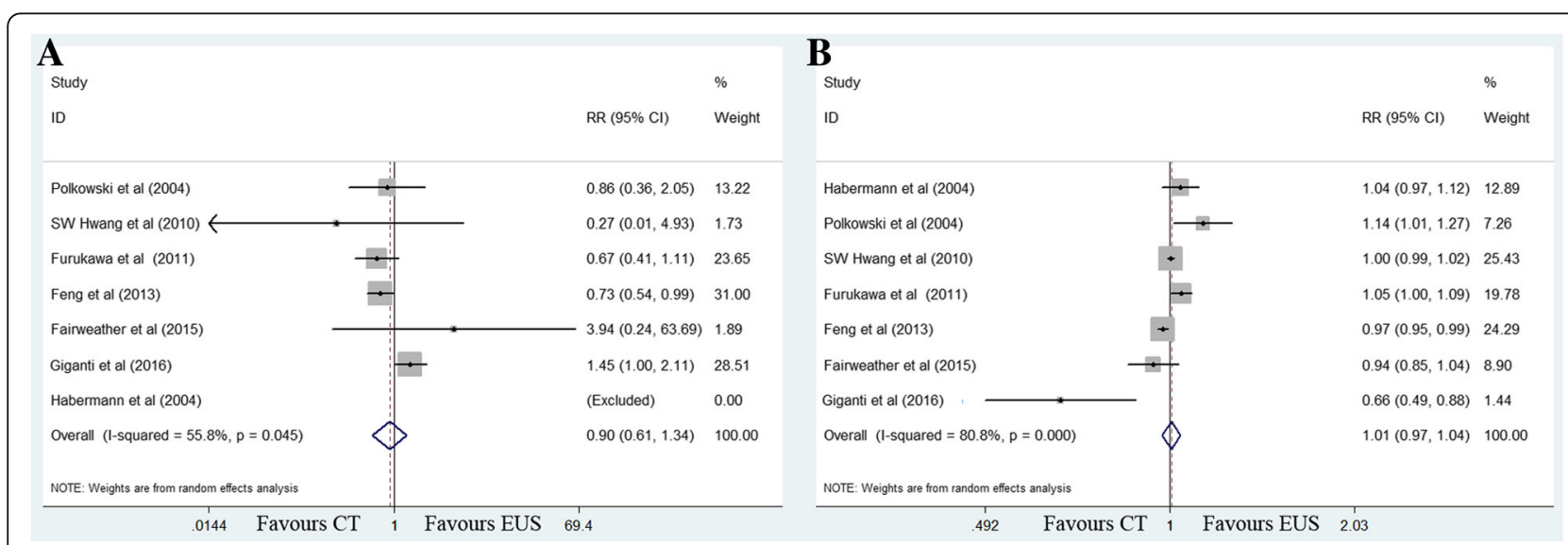

Fig. 5 Forest plots of sensitivity (a) and specificity (b) for T4 staging. MDCT, multidetector computed tomography; EUS, Endoscopic ultrasonography. RR, relative risk; $\mathrm{Cl}$, confidence interval 


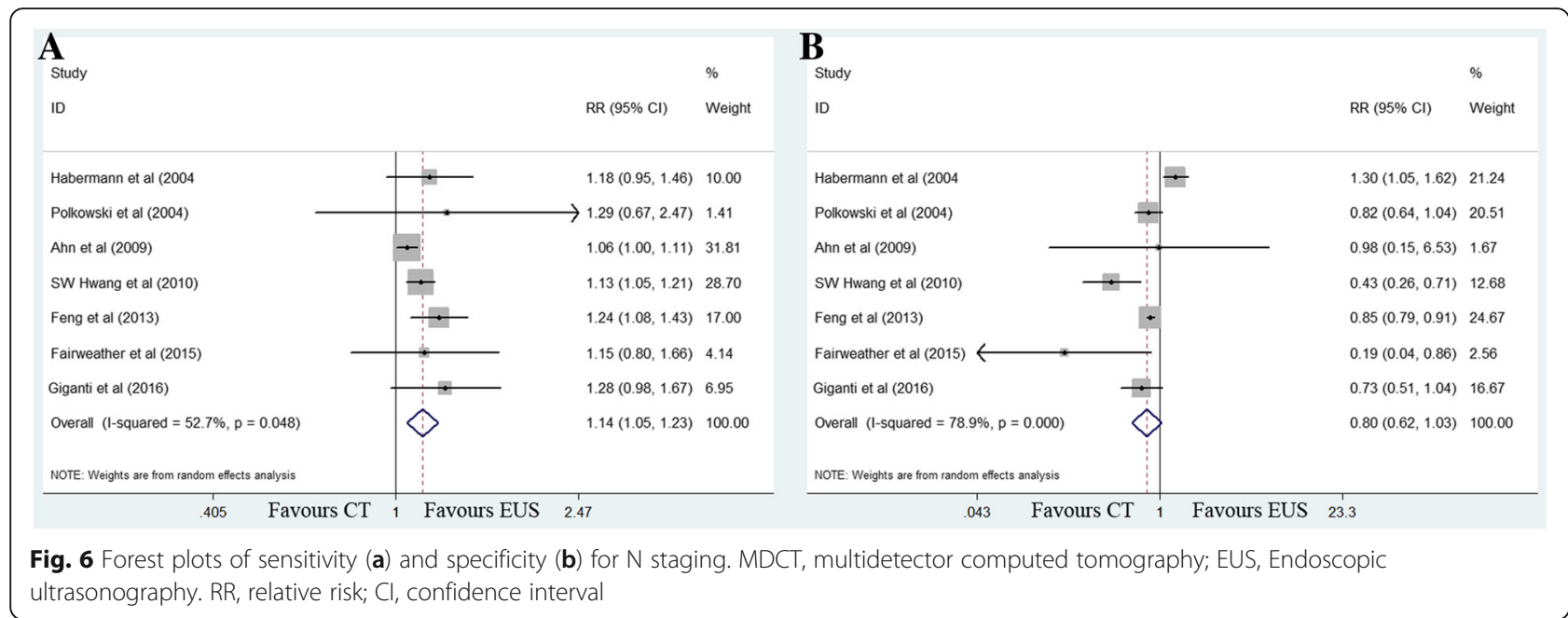

low-density zone that corresponded to the submucosa was applied to distinguish T1 and T2. However, MDCT could easily distort the results in some cases due to edema or fatty deposition [26].

Feng et al. revealed that MDCT showed higher sensitivity than EUS with regard to lymph node metastasis [15], whereas other studies suggested comparable results in $\mathrm{N}$ staging $[10,11,13,19]$. The pooled results of this meta-analysis demonstrated that EUS was superior to MDCT in preoperative $\mathrm{N}$ staging, with a higher sensitivity and better diagnostic performance. Our study revealed that EUS was more sensitive to recognize positive lymph node involvement and thus apply perioperative chemotherapy, which can reduce the tumor stage and significantly improved progression-free and overall survival $[8,9]$.

Notably, the pooled specificity values of EUS and MDCT were both quite low (49\% for EUS and 63\% for MDCT, respectively), indicating that the pooled value might not be reliable, even if EUS or MDCT suggested negative lymph node involvement. It is possible that in some cases, pathological positive lymph nodes may appear to be small without obvious enhancement. Zhao et al. also demonstrated that the rate of lymph node metastasis of EGC is quite high (25.27\%), and EMR or ESD should be cautiously used in high-risk EGC patients [27]. Therefore, more accurate imaging modalities to predict the negative lymph node for EGC are needed, and further studies are required to test whether the combination of MDCT and EUS could improve the specificity of $\mathrm{N}$ staging.

There are also some limitations in the present metaanalysis. First, the main limitation is that most of the included studies were retrospective, with the exception of three prospective studies. Second, significant betweenstudy heterogeneity was noted in this meta-analysis. Finally, the incorporation of various classification systems may have influenced the results of this meta-analysis. However, we applied strict criteria to include highquality studies, and the use of random-effects modeling

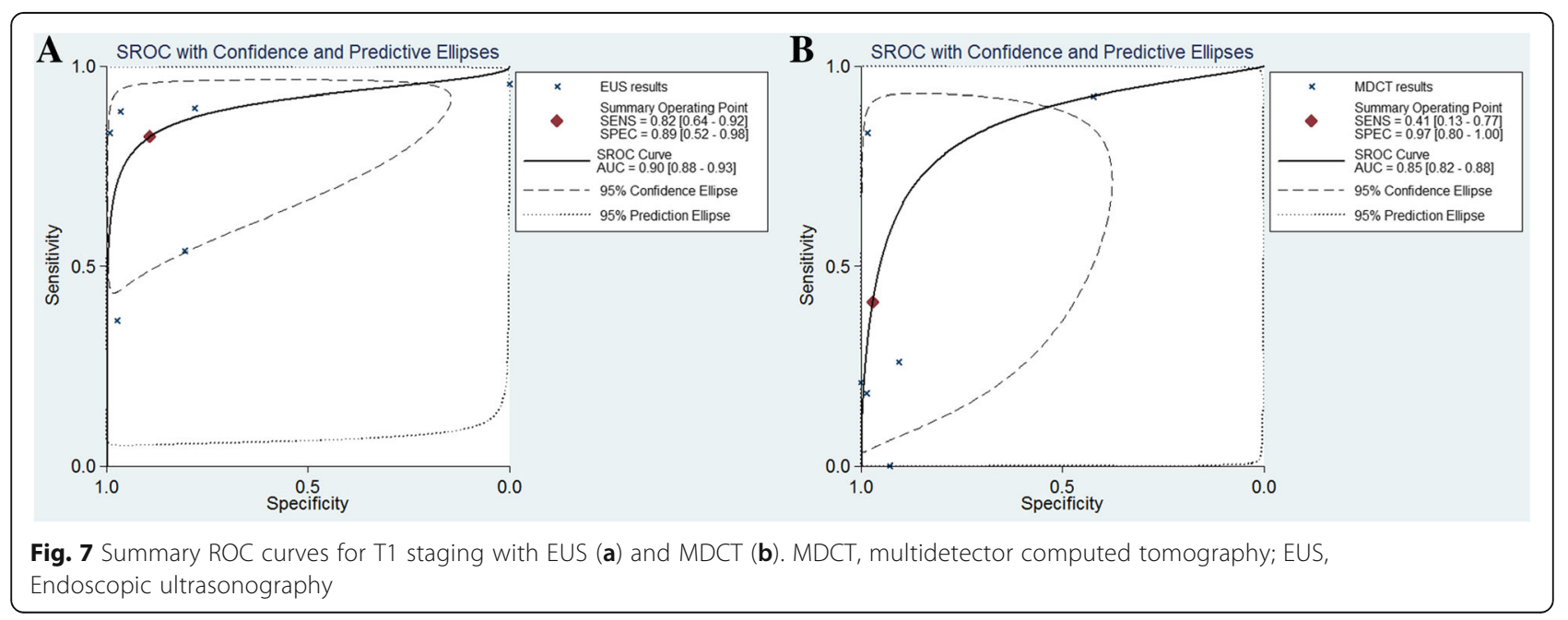



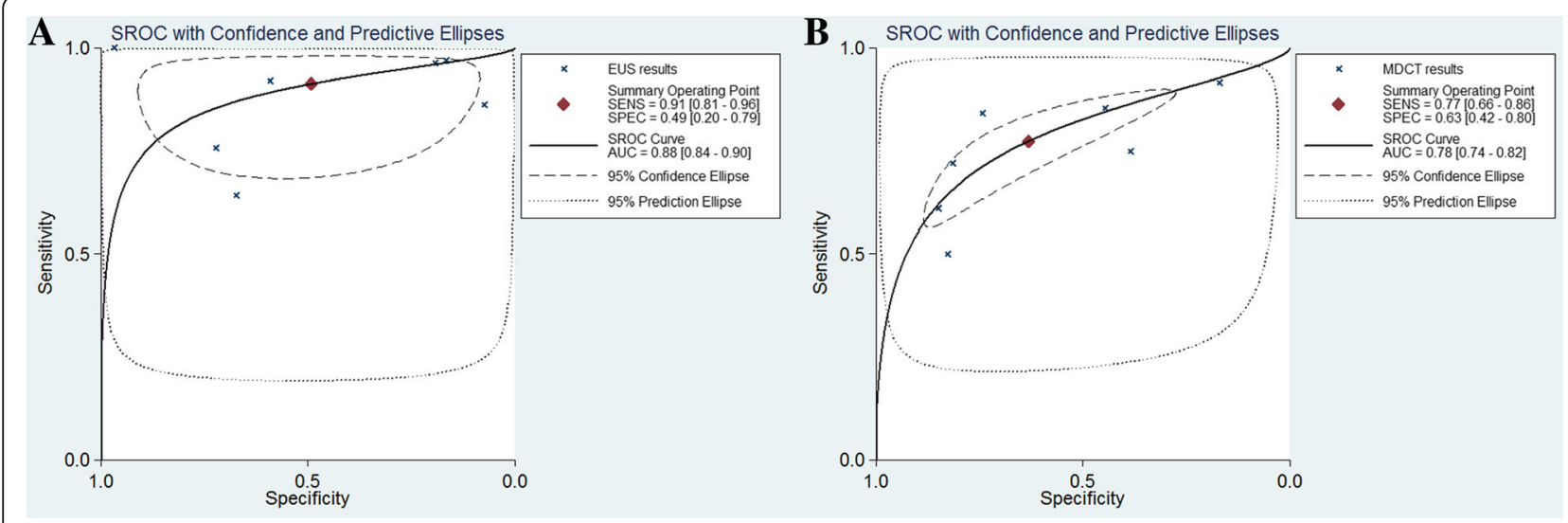

Fig. 8 Summary ROC curves for lymph node involvement with EUS (a) and MDCT (b). MDCT, multidetector computed tomography; EUS, Endoscopic ultrasonography

could adequately address the heterogeneity. In addition, $\mathrm{T}$ staging of all editions is similar; therefore, the comparison of pooled data was not influenced. Given that $\mathrm{N}$ staging varies in different editions, the present metaanalysis compared only the preoperative identification of N0 versus $\mathrm{N}+$ disease of EUS and MDCT to make the included studies comparable.

\section{Conclusions}

This meta-analysis indicates that EUS may be superior to MDCT in preoperative $\mathrm{T} 1$ and $\mathrm{N}$ staging. Additionally, the low specificity of both EUS and MDCT for N staging merits further attention.

\section{Acknowledgements}

The authors thank Miss. Minglan Shi for her encouragement support.

\section{Funding}

This work was supported in part by a grant from National Natural Science Foundation of China (81302144) and the Guangdong Science and Technology Department (No2012B061700087).

\section{Availability of data and materials}

All data generated or analysed during this study are included in this published article.

\section{Authors' contributions}

RCN independently searched references and took charge of data statistics and drafted the manuscript. RCN and SC searched references and extracted the parameters from each study. SQY, XJC, LPX, YMC, BYZ, XWS, ZWZ and $Y B C$ participated in the manuscript revision. All authors read and approved the final manuscript.

\section{Competing interests}

The authors declare that they have no competing interests.

\section{Consent for publication}

Not applicable.

Ethics approval and consent to participate Not applicable.

\section{Publisher's Note}

Springer Nature remains neutral with regard to jurisdictional claims in published maps and institutional affiliations.

\section{Author details}

${ }^{1}$ Sun Yat-sen University Cancer Center; State Key Laboratory of Oncology in South China; Collaborative Innovation Center for Cancer Medicine, 651 E Dongfeng Road, Guangzhou, Guangdong 510060, China. ${ }^{2}$ Department of Gastric Surgery, The 6th Affiliated Hospital, Sun Yat-sen University, Guangzhou, China.

Received: 30 September 2016 Accepted: 22 May 2017

Published online: 02 June 2017

\section{References}

1. Torre LA, Bray F, Siegel RL, Ferlay J, Lortet-Tieulent J, et al. Global cancer statistics, 2012. CA Cancer J Clin. 2015;65:87-108.

2. Bang YJ, Kim YW, Yang HK, Chung HC, Park YK, et al. Adjuvant capecitabine and oxaliplatin for gastric cancer after D2 gastrectomy (CLASSIC): a phase 3 open-label, randomised controlled trial. Lancet. 2012;379:315-21.

3. Sasako M, Sakuramoto S, Katai H, Kinoshita T, Furukawa H, et al. Five-year outcomes of a randomized phase III trial comparing adjuvant chemotherapy with S-1 versus surgery alone in stage II or III gastric cancer. J Clin Oncol. 2011:29:4387-93.

4. Songun I, Putter H, Kranenbarg EM, Sasako M, van de Velde CJ. Surgical treatment of gastric cancer: 15-year follow-up results of the randomised nationwide Dutch D1D2 trial. Lancet Oncol. 2010:11:439-49.

5. Uedo N, lishi H, Tatsuta M, Ishihara R, Higashino K, et al. Longterm outcomes after endoscopic mucosal resection for early gastric cancer. Gastric Cancer. 2006:9:88-92.

6. Isomoto H, Shikuwa S, Yamaguchi N, Fukuda E, Ikeda K, et al. Endoscopic submucosal dissection for early gastric cancer: a large-scale feasibility study. Gut. 2009;58:331-6.

7. National Comprehensive Cancer Network (NCCN). Clinical Practice Guidelines in Oncology. Gastric Cancer, Version 1. 2017. https://www.nccn. org/professionals/physician gls/f guidelines.asp. Accessed 29 May 2017.

8. Cunningham D, Allum WH, Stenning SP, Thompson JN, Van de Velde CJ, et al. Perioperative chemotherapy versus surgery alone for resectable gastroesophageal cancer. N Engl J Med. 2006;355:11-20.

9. Ychou M, Boige V, Pignon JP, Conroy T, Bouche O, et al. Perioperative chemotherapy compared with surgery alone for resectable gastroesophageal adenocarcinoma: an FNCLCC and FFCD multicenter phase III trial. J Clin Oncol. 2011:29:1715-21.

10. Giganti F, Orsenigo E, Arcidiacono PG, Nicoletti R, Albarello L, et al. Preoperative locoregional staging of gastric cancer: is there a place for magnetic resonance imaging? Prospective comparison with EUS and multidetector computed tomography. Gastric Cancer. 2016;19:216-25 
11. Polkowski M, Palucki J, Wronska E, Szawlowski A, Nasierowska-Guttmejer A, et al. Endosonography versus helical computed tomography for locoregional staging of gastric cancer. Endoscopy. 2004;36:617-23.

12. Ahn HS, Lee HJ, Yoo MW, Kim SG, Im JP, et al. Diagnostic accuracy of T and $\mathrm{N}$ stages with endoscopy, stomach protocol $\mathrm{CT}$, and endoscopic ultrasonography in early gastric cancer. J Surg Oncol. 2009;99:20-7.

13. Hwang SW, Lee DH, Lee SH, Park YS, Hwang JH, et al. Preoperative staging of gastric cancer by endoscopic ultrasonography and multidetector-row computed tomography. J Gastroenterol Hepatol. 2010;25:512-8.

14. Furukawa K, Miyahara R, Itoh A, Ohmiya N, Hirooka Y, et al. Diagnosis of the invasion depth of gastric cancer using MDCT with virtual gastroscopy: comparison with staging with endoscopic ultrasound. AJR Am J Roentgenol. 2011;197:867-75.

15. Feng XY, Wang W, Luo GY, Wu J, Zhou ZW, et al. Comparison of endoscopic ultrasonography and multislice spiral computed tomography for the preoperative staging of gastric cancer - results of a single institution study of 610 Chinese patients. PLoS One. 2013:8:e78846.

16. Fairweather M, Jajoo K, Sainani N, Bertagnolli MM, Wang J. Accuracy of EUS and CT imaging in preoperative gastric cancer staging. J Surg Oncol. 2015;111:1016-20.

17. Higgins J, Sally G. Cochrane handbook for systematic reviews of interventions. New York: Cochrane Collaboration, John Wiley and Sons; 2008.

18. Egger M, Davey Smith G, Schneider M, Minder C. Bias in meta-analysis detected by a simple, graphical test. BMJ. 1997;315:629-34.

19. Habermann $C R$, Weiss F, Riecken $R$, Honarpisheh $H$, Bohnacker $S$, et al. Preoperative staging of gastric adenocarcinoma: comparison of helical CT and endoscopic US. Radiology. 2004;230:465-71.

20. Shimoyama S, Yasuda H, Hashimoto M, Tatsutomi Y, Aoki F, et al. Accuracy of linear-array EUS for preoperative staging of gastric cardia cancer. Gastrointest Endosc. 2004;60:50-5.

21. Xi WD, Zhao C, Ren GS. Endoscopic ultrasonography in preoperative staging of gastric cancer: determination of tumor invasion depth, nodal involvement and surgical resectability. World J Gastroenterol. 2003;9:254-7.

22. Kim JW, Shin SS, Heo SH, Choi YD, Lim HS, et al. Diagnostic performance of 64-section CT using $C T$ gastrography in preoperative $T$ staging of gastric cancer according to 7th edition of AJCC cancer staging manual. Eur Radiol. 2012;22:654-62.

23. Yu T, Wang X, Zhao Z, Liu F, Liu X, et al. Prediction of T stage in gastric carcinoma by enhanced $\mathrm{CT}$ and oral contrast-enhanced ultrasonography. World J Surg Oncol. 2015;13:184

24. Barros RH, Penachim TJ, Martins DL, Andreollo NA, Caserta NM. Multidetector computed tomography in the preoperative staging of gastric adenocarcinoma. Radiol Bras. 2015;48:74-80.

25. Pei Q, Wang L, Pan J, Ling T, Lv Y, et al. Endoscopic ultrasonography for staging depth of invasion in early gastric cancer: A meta-analysis. J Gastroenterol Hepatol. 2015;30:1566-73.

26. Fukuya T, Honda H, Kaneko K, Kuroiwa T, Yoshimitsu K, et al. Efficacy of helical CT in T-staging of gastric cancer. J Comput Assist Tomogr. 1997;21:73-81.

27. Zhao BW, Chen YM, Jiang SS, Chen YB, Zhou ZW, et al. Lymph node metastasis, a unique independent prognostic factor in early gastric cancer. PLoS One. 2015;10:e0129531.

\section{Submit your next manuscript to BioMed Central and we will help you at every step:}

- We accept pre-submission inquiries

- Our selector tool helps you to find the most relevant journal

- We provide round the clock customer support

- Convenient online submission

- Thorough peer review

- Inclusion in PubMed and all major indexing services

- Maximum visibility for your research

Submit your manuscript at www.biomedcentral.com/submit

) Biomed Central 